\title{
Discontinuation of hormonal contraception in Oman: prevalence and reasons
}

Fatma Al-Ghashri, ${ }^{1}$ Habiba Al-Harthi, ${ }^{1}$ Maryam Al Shukri ${ }^{2}$ and Asma Al Shidhani ${ }^{3}$

${ }^{1}$ Primary Health Care, Ministry of Health, Muscat, Oman. ${ }^{2}$ Department of Obstetrics and Gynecology, Sultan Qaboos University Hospital, Muscat, Oman (Correspondence to: M. Alshukri: mnalshukri@gmail.com; mariamn@squ.edu.om). 3Department of Family Medicine and Public Health, College of Medicine and Health Sciences, Sultan Qaboos University Hospital, Muscat, Oman.

\begin{abstract}
Background: Discontinuation of hormonal contraceptives is an important contributor to unmet need of contraception. Aims: To determine the discontinuation rate and the reasons for discontinuation of hormonal contraception among Omani women.

Methods: This was a 2-stage sampling, multicentre, retrospective cohort study conducted in 2018 at primary health care centres in Muscat Region, Oman. It included newly registered users of hormonal contraceptives in birth spacing clinics from January to December 2016 and the course of care over the following 12 months. A telephone interview was conducted to complement some of the missing data. The contraceptive methods available were combined oral contraceptives, progesterone only pills and injectable depot medroxyprogesterone acetate.

Results: We included 404 women and $87.8 \%$ were breast-feeding. By the end of the first year, $(268$; 66.3\%) women discontinued their contraceptive method. More than half $(55.2 \% 148 / 268)$ of the discontinuation was attributed to adverse effects and the most prevalent was menstrual abnormality (102/268; 38.1\%). Only 5.6\% (15/268) discontinued contraception because they desired pregnancy. Partners and logistics of availability and access played a minimal role in discontinuation. Age and number of children did not influence the discontinuation rate.

Conclusion: This study improves our knowledge about the rate of discontinuation of hormonal contraception and its related factors in Oman, which can be used for population-specific counselling. Future research should study the contraception behaviour of breast-feeding women to assess when and why they discontinue their contraceptive methods.

Keywords: breast-feeding, hormonal contraception, menstruation disturbances, Oman, treatment discontinuation

Citation: Al-Ghashri F; Al-Harthi H; Al Shukri M; Al Shidhani A. Discontinuation of hormonal contraception in Oman: prevalence and reasons. East Mediterr Health J. 2021;27(10):993-1000. https://doi.org/10.26719/emhj.21.031

Received: 05/03/20; accepted: 04/03/21

Copyright (c) World Health Organization (WHO) 2021. Open Access. Some rights reserved. This work is available under the CC BY-NC-SA 3.0 IGO license (https://creativecommons.org/licenses/by-nc-sa/3.o/igo)
\end{abstract}

\section{Introduction}

Family planning is an important contributor to reducing mortality and morbidity in mothers, neonatal infants and children under 5 years of age $(1,2)$. Global improvements in several aspects related to family planning have resulted in increased contraceptive use and have reduced the unmet need for family planning $(2,3)$.

Discontinuation of contraception is an important contributor to the unmet need of contraception (4). The prevalence of contraceptive discontinuation varies worldwide. It is reported to be as high as $81 \%$ in Brazil and as low as $24 \%$ in the United States of America (USA) (5). Discontinuation of hormonal contraceptives within 1 year of use is a particular concern as they are generally effective and safe when used in accordance with medical eligibility criteria $(6,7)$. Discontinuation of contraception can take different forms, such as switching the method or abandonment altogether (8). Like the use of contraception, its discontinuation is multifactorial $(8-10)$. Such factors include women's age, education, socioeconomic status and number of children $(8,11,12)$. The reported reasons for discontinuation of contraception include adverse effects, the logistics of availability and access, partner's preference, and method failure $(5,13)$. The discontinuation of hormonal contraceptives due to adverse effects ranges from $24 \%$ in Spain to $57 \%$ in Brazil $(4,5,8,14)$.

In Oman, contraceptive services have been incorporated under primary health care since 1994 $(15,16)$. Contraception is provided free of charge to all Omani women through self-referral to contraception clinics at local health centres $(17,18)$. Although several studies have explored contraceptive choices of women in Oman, there have been no studies on discontinuation of contraception, especially the hormonal type.

The primary objectives of this study were to determine the rate of discontinuation and the reasons for discontinuation of hormonal contraception among Omani women. The secondary objectives were to assess the prevalence of adverse effects of hormonal contraception reported by users and their contribution to discontinuation. 


\section{Methods}

\section{Study design}

This was a 2-stage multicentre, descriptive cohort study conducted in 2018 at primary healthcare centres in Muscat Governorate, Oman. It included newly registered users of hormonal contraceptives in the birth spacing clinics between 1 January and 31 December 2016, and the course of care over the following 12 months was recorded. In 2018, there were 29 local health centres in Muscat Governorate, and 21 had a dedicated birth spacing clinic offering contraception services. There were 3 forms of hormonal contraception available at that time. The oral forms included: progestogen only pill (POP) of levonorgestrel $0.15 \mathrm{mg}$ or norethindrone $0.35 \mathrm{mg}$, and combined oral contraceptive $(\mathrm{COC})$ containing levonorgestrel 0.15 $\mathrm{mg}$ and ethenylestradiol $0.03 \mathrm{mg}$. The injectable contraceptive was depot medroxyprogesterone acetate (DMPA) $150 \mathrm{mg}$.

\section{Study population}

The sample included Omani women aged 15-49 years registered as new clients in the birth spacing clinics in 2016. Non-Omani women (who married Omani men), women using nonhormonal contraceptives and women who declined participation were excluded.

\section{Estimation of sample size}

According to Oman National Center for Statistics and Information, there were 139394 women of reproductive age (15-49 years) in Muscat Region in 2016; $28.4 \%$ of the total population of 490525 (19). It was estimated that the rate of contraception use among women was $41.3 \%$ (19). The calculated sample size was 384 (based on $95 \%$ confidence level, $5 \%$ margin of error, and 50\% anticipated prevalence of contraceptive discontinuation. Two-stage sampling was conducted to randomly select samples from the 29 local health centres in Muscat Region. In the first stage, a simple random sample of 12 local health centres (clusters) was selected using a lottery method. In the second stage, a simple random subsample was used to select the participants within each of these 12 centres. The investigators opted to increase the sample size to 500 to accommodate nonresponders (opt-out or incomplete data). Computer-generated randomization was used for each contraceptive clinic in these 12 local health centres, and the registered file numbers for new clients in 2016 were entered in a separate Excel sheet. A corresponding list of random numbers was created electronically by Excel and arranged in ascending sequence. The top 41 or 42 of each list were chosen to be included in the study to constitute the sample of 500 clients.

\section{Data collection}

A 40-variable data collection sheet was constructed. The variables were factors that could play a role in discontinuation of contraception as described previously $(7,20,21)$. The first section of the data collection sheet included variables related to sociodemographic data and menstrual, obstetric, gynaecological and medical history. The second part focused on contraception behaviour, including method used, duration of use, changes in baseline health, history of adverse effects, attitudes and satisfaction with the method, and factors contributing to discontinuation (20). The data sheet was piloted on 20 clients to evaluate its applicability and feasibility. Some modifications were made based on the data available for collection and the feedback provided by clients. The data were collected from the registry of the birth spacing clinic and electronic medical records over the first year of follow-up. A telephone interview was conducted with the clients to assess their satisfaction with the contraceptive method used and to supplement any missing data that were not available from the records. All the interviews were conducted by 2 researchers and all the clients in the cohort were approached.

\section{Statistical analysis}

Descriptive statistical analysis was performed using SPSS version 23. Frequencies and percentages were used for categorical variables. The $\mathrm{c}^{2}$ test was used for testing the association between categorical variables. $\mathrm{P} \leq$ 0.05 was considered statistically significant. Odds ratios (ORs) and 95\% confidence intervals (CIs) were used to assess the effect of age, educational level and number of children on discontinuation of hormonal contraceptives.

\section{Ethical approval}

The study was approved by the Research and Ethics Committee of the Directorate General of Health Services, of Muscat Governorate, Ministry of Health, Oman, with the reference number MH-DGPS-MG-7/2019.

\section{Results}

\section{Study population}

Of the identified 500 new contraception users, 82 were excluded because they were not reachable by phone $(n=$ 82 ) or they declined to give consent $(n=14)$. We included 404 women, which translated into $80.8 \%$ response rate. Three hundred and fifty-five $(87.87 \%)$ were breast feeding when they started contraception and 285 (70.54\%) were new to the contraceptive method. The most prevalent hormonal contraceptive choice was DMPA (187; $46.29 \%)$, followed by POP $(140 ; 34.65 \%)$ and COC was the least prevalent $(77 ; 19.06 \%)$. The sociodemographic characteristics of the sample and the method of hormonal contraception used are shown in Table 1.

\section{Choice of contraceptive method}

When women were asked about the main reason for choosing their method of contraception, 106 (26.26\%) answered that they were influenced by a previous bad experience with another method or reports of bad experiences from other women. That was the main motivator for $31(40.3 \%)$ COC and 58 (41.43\%) POP users. Eighty-five 


\begin{tabular}{|c|c|c|c|}
\hline Characteristics & $\begin{array}{c}\operatorname{COC} n=77 \\
n(\%)\end{array}$ & $\begin{array}{c}\text { POP } n=140 \\
n(\%)\end{array}$ & $\begin{array}{c}\text { DMPA } n=187 \\
n(\%)\end{array}$ \\
\hline \multicolumn{4}{|l|}{ Age, yr } \\
\hline $18-25$ & $15(19.48)$ & $44(31.43)$ & $48(25.67)$ \\
\hline $26-30$ & $33(42.86)$ & $39(27.86)$ & $56(29.95)$ \\
\hline $31-35$ & $18(23.38)$ & $34(24.29)$ & $46(24.60)$ \\
\hline $36-40$ & 7 (9.09) & $19(13.57)$ & $26(13.90)$ \\
\hline$>40$ & $4(5.19)$ & $4(2.86)$ & $11(5.88)$ \\
\hline \multicolumn{4}{|l|}{ Educational level } \\
\hline Illiterate & $2(2.60)$ & $2(1.43)$ & $4(2.14)$ \\
\hline Write and read & $3(3.90)$ & $5(3.57)$ & $14(7.49)$ \\
\hline Primary & $9(11.69)$ & $12(8.57)$ & $31(16.58)$ \\
\hline Secondary & $39(50.66)$ & $71(50.71)$ & $94(50.27)$ \\
\hline Advance & $24(31.17)$ & $50(35.71)$ & $44(23.53)$ \\
\hline \multicolumn{4}{|l|}{ No. of children } \\
\hline 0 & $1(1.30)$ & $1(0.71)$ & 0 \\
\hline $1-3$ & $55(71.43)$ & $96(68.57)$ & $119(63.63)$ \\
\hline $4-6$ & $18(23.38)$ & $34(24.29)$ & $52(27.81)$ \\
\hline$>6$ & $3(3.90)$ & $9(6.43)$ & $16(8.56)$ \\
\hline \multicolumn{4}{|c|}{ Lactating when starting contraception } \\
\hline Yes & $63(81.82)$ & 128 (91.43) & $164(87.70)$ \\
\hline No & $14(18.18)$ & $12(8.57)$ & $21(11.23)$ \\
\hline Not sure & 0 & 0 & $2(1.07)$ \\
\hline
\end{tabular}

$\mathrm{COC}=$ combined oral contraceptive $; \mathrm{DMPA}=$ depo medroxyprogesterone acetate $; \mathrm{POP}=$ progesterone-only pill.

(45.45\%) of the DMPA users chose the method because they could not remember to take a daily pill. Twenty-eight (6.98\%) women chose their method due to rapid return of fertility after discontinuation. Fifty-six (13.86\%) women choose their method because they thought it provided more reliable contraception compared to other methods.

\section{Prevalence of contraceptive discontinuation}

By the end of the first year, more than half of the women in the study $(268 ; 66.34 \%)$ discontinued their contraceptive method: switching to another contraceptive method (86; $32.09 \%)$; ceasing to use contraception all together (182; $67.91 \%)$; or failure of the contraceptive method, resulting in pregnancy $(1 ; 0.25 \%)$.

\section{Method-specific discontinuation rate}

One hundred and thirty-two of 140 (94.29\%) POP, 101/187 (54.01\%) DMPA and 35/77 (45.45\%) COC users discontinued contraception within 12 months $(\mathrm{P}=0.0001)$. Most of these women decided to discontinue contraception within the first 6 months: $77 \%$ of POP, $65 \%$ of DMPA and $63 \%$ of $\mathrm{COC}$ users.

\section{Risk of discontinuation by demographic factors}

There was no association between discontinuation of contraception and age $(P=0.895)$. When comparing women aged $\leq 30$ with those $>30$ years, the difference was insignificant $(P=0.98)$ and age had no effect (OR: 1.01; 95\% CI: $0.66-1.53$ ). Around $74 \%$ of clients with uni- versity level education and $70 \%$ of those who finished secondary school discontinued contraception. Only $36 \%$ of clients who were able to only read and write discontinued contraception, which was a significant difference $(P<0.001)$. We grouped together those who had no or limited education into 1 group $(n=82)$ and those who had a secondary school or higher education in another group $(n=322)$ and compared the discontinuation risk (37/82 and 231/322). Educated women had almost 3 times the chance to discontinue their hormonal contraception compared to those with no or limited education (OR: 3.09; $95 \%$ CI: $1.88-5.08)$. All except 2 women had children. The 2 nulliparous women were both using COC and discontinued contraception within the first 6 months. One desired pregnancy and the other discontinued on the advice of her healthcare provider to switch contraception. Among the parous women, there was no difference in discontinuation rate between clients who had 1-3 or those who had $>3$ children $(P=0.98)$. To confirm this, the OR for high parity ( $>3$ children) in relation to discontinuation of hormonal contraceptives was insignificant (OR: 1.14 95\% CI: 0.73-1.76).

\section{Reasons for contraceptive discontinuation}

More than half $(55.22 \% 148 / 268)$ of the discontinuation was attributed to adverse effects of the contraceptive method and only $5.60 \%$ (15/268) of women discontinued contraception because they desired pregnancy. Eightysix $(32 \%)$ discontinued contraception on the advice of her 
healthcare provider to switch the contraception. Other reasons for discontinuation such as logistics, husband's death, divorce, preference for a natural method and contraceptive failure had small percentages $(7 \%)$. Mood changes were reported by $25 \%, 21 \%$ and $26 \%$ of clients who used COC, POP and DMPA, respectively. COC users were more likely to discontinue because of this adverse effect. Seventy-five percent of clients who discontinued because of mood changes did so within the first 6 months.

\section{Discontinuation due to different adverse effects}

Sixteen percent $(65 / 404)$ of women gained weight but most of these $(75.4 \% ; 49 / 65)$ gained $<5 \mathrm{~kg}$. One women using COC gained $>10 \mathrm{~kg}$. Table 2 shows the prevalence of adverse effects and their contribution to discontinuation of contraception.

\section{Contraception counselling and advice regarding adverse effects}

The majority $(82 \%)$ of clients felt they were adequately counselled about possible adverse effects of the contraceptive method prior to initiation. Most women who experienced adverse effects $(70 \%)$ reported them to their healthcare provider. Only 5.6\% of those who reported adverse effects did not receive any management advice.

\section{Satisfaction with method of contraception}

When women were asked whether they were satisfied overall with their contraceptive method, most of those who discontinued contraception $(58.96 \% ; 158 / 268)$ were unsatisfied. When compared to women who continued the method, only $2 \%(3 / 136)$ were unsatisfied $(\mathrm{P}=0.00)$.

\section{Discussion}

This study showed that women in Oman preferred to use progestogen-only contraceptives; $46 \%$ used DMPA and $34 \%$ used POP. This was expected since $87.9 \%$ of the women in the study initiated contraception while breastfeeding. The medical eligibility criteria of the WHO and the local standard procedures have a preference for progestogen-only contraceptives during breastfeeding (19). This is due to widespread concern about COC decreasing milk volume, altering its content, and passage of the hormonal content to the infant. This believe is strongly held by healthcare professionals and contraceptive users. This is still debated, as 2 systematic reviews failed to give a clear verdict of whether $\mathrm{COC}$ has a negative effect on milk volume and composition or child growth $(22,23)$.

The most represented age group for all methods of contraception in our study was $25-30$ years $(31 \%)$. The women in our study were older than the women in a French study who were predominantly aged $20-25$ years (13). This might be because our women were all married, whereas the French study included women using contraception who were sexually active regardless of their type of relationship (13).

Avoidance of a negative experience was a significant motivator in choosing a contraceptive method. A bad experience of the client herself or her friends or relatives played an important part in choosing contraceptive method. This highlights the importance of precontraception counselling and explaining that adverse effects can vary among women and the same woman can have a different experience with the same method (24).

The rate of discontinuation of hormonal contraception within the first year in our study was $66.8 \%$, which is higher than the rate in Germany (30\%), Senegal (34\%), Italy

\begin{tabular}{|c|c|c|c|c|c|c|c|c|}
\hline $\begin{array}{l}\text { Method } \\
\text { Adverse effect }\end{array}$ & $\begin{array}{c}\text { All } \\
\text { methods } \\
\text { users } \\
n=404\end{array}$ & $\begin{array}{l}\text { All methods } \\
\text { discontinued }\end{array}$ & $\begin{array}{c}\text { COC } \\
\text { users } \\
n=77\end{array}$ & $\begin{array}{c}\mathrm{COC} \\
\text { discontinued }\end{array}$ & $\begin{array}{c}\text { POP } \\
\text { Users } \\
n=140\end{array}$ & $\begin{array}{c}\text { POP } \\
\text { discontinued }\end{array}$ & $\begin{array}{c}\text { DMPA } \\
\text { users } \\
n=187\end{array}$ & $\begin{array}{c}\text { DMPA } \\
\text { discontinued }\end{array}$ \\
\hline Weight gain & $\begin{array}{c}67 \\
(16.58 \%)\end{array}$ & $\begin{array}{c}7 \\
(1.73 \%)\end{array}$ & $\begin{array}{c}8 \\
(10.39 \%)\end{array}$ & $\begin{array}{c}1 \\
(1.30 \%)\end{array}$ & $\begin{array}{c}18 \\
(12.86 \%)\end{array}$ & $\begin{array}{c}3 \\
(2.14 \%)\end{array}$ & $\begin{array}{c}41 \\
(21.93 \%)\end{array}$ & $\begin{array}{c}3 \\
(1.60 \%)\end{array}$ \\
\hline Headache & $\begin{array}{c}20 \\
(4.95 \%)\end{array}$ & $\begin{array}{c}6 \\
(1.49 \%)\end{array}$ & $\begin{array}{c}14 \\
(18.18 \%)\end{array}$ & 0 & $\begin{array}{c}21 \\
(15.0 \%)\end{array}$ & $\begin{array}{c}5 \\
(3.57 \%)\end{array}$ & $\begin{array}{c}37 \\
(19.79 \%)\end{array}$ & $\begin{array}{c}1 \\
(0.53 \%)\end{array}$ \\
\hline $\begin{array}{l}\text { Sexual } \\
\text { dysfunction }\end{array}$ & $\begin{array}{c}7 \\
(1.73 \%)\end{array}$ & 0 & $\begin{array}{c}1 \\
(1.30 \%)\end{array}$ & 0 & $\begin{array}{c}2 \\
(1.43 \%)\end{array}$ & 0 & $\begin{array}{c}4 \\
(2.14 \%)\end{array}$ & 0 \\
\hline Mood changes & $\begin{array}{c}97 \\
(24.01 \%)\end{array}$ & $\begin{array}{c}20 \\
(4.95 \%)\end{array}$ & $\begin{array}{c}19 \\
(24.68 \%)\end{array}$ & $\begin{array}{c}9 \\
(11.69 \%)\end{array}$ & $\begin{array}{c}29 \\
(20.71 \%)\end{array}$ & $\begin{array}{c}6 \\
(4.29 \%)\end{array}$ & $\begin{array}{c}49 \\
(26.20 \%)\end{array}$ & $\begin{array}{c}5 \\
(2.67 \%)\end{array}$ \\
\hline GI symptoms & $\begin{array}{c}24 \\
(5.94 \%)\end{array}$ & $\begin{array}{c}8 \\
(1.98 \%)\end{array}$ & $\begin{array}{c}2 \\
(2.60 \%)\end{array}$ & $\begin{array}{c}1 \\
(1.30 \%)\end{array}$ & $\begin{array}{c}14 \\
(10.0 \%)\end{array}$ & $\begin{array}{c}7 \\
(5.0 \%)\end{array}$ & $\begin{array}{c}8 \\
(4.27 \%)\end{array}$ & 0 \\
\hline $\begin{array}{l}\text { Venous thrombo- } \\
\text { embolism }\end{array}$ & $\begin{array}{c}1 \\
(0.02 \%)\end{array}$ & $\begin{array}{c}1 \\
(0.25 \%)\end{array}$ & 0 & 0 & 0 & 0 & $0.53 \%(1)$ & $\begin{array}{c}1 \\
(0.53 \%)\end{array}$ \\
\hline $\begin{array}{l}\text { Menstrual } \\
\text { abnormalities }\end{array}$ & $\begin{array}{c}212 \\
(52.48 \%)\end{array}$ & $\begin{array}{c}102 \\
(25.25 \%)\end{array}$ & $\begin{array}{c}16 \\
(20.78 \%)\end{array}$ & $\begin{array}{c}5 \\
(6.49 \%)\end{array}$ & $\begin{array}{c}59 \\
(42.14 \%)\end{array}$ & $\begin{array}{c}30 \\
(21.43 \%)\end{array}$ & $\begin{array}{c}137 \\
(73.26 \%)\end{array}$ & $\begin{array}{c}67 \\
(35.82 \%)\end{array}$ \\
\hline $\begin{array}{l}\text { Total discontinued } \\
\text { due to side effects }\end{array}$ & & 148 & & 16 & & 51 & & 76 \\
\hline
\end{tabular}

$\mathrm{COC}=$ combined oral contraceptive $; \mathrm{DMPA}=$ depo medroxyprogesterone acetate $; \mathrm{POP}=$ progesterone-only pill. 
(34.9\%) and USA (24\%) and lower than in Turkmenistan $(72 \%)$ and Brazil $(81 \%)(4,7,9,14)$. COC had the lowest 1-year discontinuation rate (45\%), followed by DMPA (54\%), while the highest rate was for POP (94\%). The specific discontinuation rates for DMPA and COC in our study are close to $53 \%$ and $42 \%$ reported in the USA (25). The POP discontinuation rate in our study is the highest reported to date (26). Healthcare providers usually advise women to switch their method of contraception from POP after 6 months. This can be for management of breakthrough bleeding, which is more common in POP compared to $\operatorname{COC}(10,27)$. Another reason to advise discontinuation of POP after 6 months of breastfeeding might be concern over reduced efficacy when women start complementary feeding and breastfeeding becomes less regular. However, a systemic review did not show effectiveness to be an issue (28). Also, WHO eligibility criteria describe POP as category 1 with no restriction for breastfeeding women who are $\geq 6$ months postpartum (23). A third reason might be to provide more flexibility of time because POP has a narrow window of only 3 hours for when women should be taking their daily dose (29).

Previous studies have found that women's age, educational level and number of children are important determinants of decision to use contraception $(17,20,30)$. However, we did not find age or number of children to be important in the decision to discontinue contraception. In Jordan, which shares many social characteristics with Oman, older age and larger number of children predict longer duration of contraception (31). Studies in other countries have found that younger age is associated with higher rate of discontinuation (25). The impact of education on discontinuation of contraception has been of particular interest. The general tendency is to assume that highly educated women adhere to contraception and have better access to resources to cope with adverse effects (13). In our study, less-educated women were less likely to discontinue contraception, which concurs with previous studies $(8,32)$. However, other studies have found that educational level does not influence discontinuation of contraception $(4,9)$, and some have found that less-educated women are more likely to discontinue contraception (8). It is difficult to explain the effect of education on contraception in isolation because it is a surrogate for many other personal, social, economic and policy-related factors (30).

We agree that women's personal characteristics and social circumstances are important in the decision to use contraception but there is a strong believe that the method characteristics and adverse effects profile are important to women's decisions to discontinue contraception (9). All studies to date agree that adverse effects are the commonest reason for contraceptive discontinuation $(2,4,5,7,9,14)$, and in our study, adverse effects contributed to more than half of the discontinuations. Other reasons for discontinuation include desire for pregnancy and nonavailability of the method. Partnership-related factors such as husband's disapproval, loss of sexual function or divorce have contributed a small percentage
(0.38\%). In our study, only 1 woman discontinued DMPA because her husband changed his mind about her using contraception. Studies from Africa have highlighted the partners' role in discontinuation of contraception because they associate contraception with infidelity and refuse it (4). This can lead to women being secretive about contraception, which hinders compliance and seeking help for adverse effects (4). Previous studies in Oman have described the importance of husbands' approval for women's use of contraception from religious and social aspects $(20,30)$. Our study indicates that once husbands' approval for contraception has been granted, it is unlikely to be retracted.

The second most common reason for discontinuation of hormonal contraception is healthcare providers' advice to switch method. This contributed to almost one third of the total discontinuation in our study. Most healthcare providers advise women to change contraceptive method for the following reasons: development of unfavourable health risk such as hypertension, diabetes or impaired glucose tolerance, malignancy, depression or headache; belief that some contraceptives are more effective than others; and if the method is not available during followup. The advice to switch or discontinue contraceptive methods is part of the armamentarium to manage adverse effects (18). For POP, healthcare providers advise women to switch method beyond the period of exclusive breastfeeding (18).

It is reassuring to see that the logistics of availability and access to contraception have contributed minimally $(0.75 \%)$ to discontinuation. This is due to the way contraceptive services are structured to be easily accessible in terms of distance, free of charge and supplied sufficiently through local health centres (18). However, other studies have reported that availability, cost of contraception and travel, and distance are significant contributors to discontinuation $(14,24)$.

Our results agree with most studies in this field that the commonest adverse effect leading to discontinuation of hormonal contraception is change in menstrual bleeding, including breakthrough, heavy or prolonged bleeding, and amenorrhea $(7,8,10,14)$. This contributed $25 \%$ of the discontinuation in our study. Other adverse effects resulting in discontinuation are weight gain, mood changes, headache, gastrointestinal symptoms, sexual dysfunction and thromboembolism. The frequency of thromboembolism was $0.25 \%$, which is $<0.5 \%$ reported in an Italian study (7). The literature and several guidelines advocate progestogen-only contraceptives for women at risk of thromboembolism (18). However, there is evidence that although intrauterine and oral progestogens are not associated with an increased thromboembolism risk, injectable progestogens including DMPA are associated with 2.6 times the risk of thromboembolism between users and nonusers (33). Gastrointestinal symptoms including nausea, vomiting and bloating contributed about $2 \%$ of the discontinuation and they were reported more by POP users (10\%), which is similar to rates in other studies $(7,12)$. 
It is difficult to substantiate the effects of hormonal contraceptives on sexual function from the literature. The evidence is inconsistent and the pathophysiological basis of these effects is poorly understood (34). In our study, only 7 clients $(1.7 \%)$ reported that the method affected their sexual satisfaction negatively but none of them reported it as a direct reason for their discontinuation. This might be a true finding or biased considering the unease of discussing such a private matter with a researcher.

Counselling regarding adverse effects of contraceptives has been linked to lower discontinuation rate $(13,14,35)$. In our study, $82 \%$ of women felt they were adequately counselled about the adverse effects of the contraceptive method before they started. This is similar to another study of American women, in which $86 \%$ felt they were adequately informed about their contraceptive methods and the adverse effects (5). However, this high rate of adequate counselling and high discontinuation rate might be because the counselling was suboptimal in terms of quality or comprehensiveness (35). Another reason could be that the women retained little of what they were counselled about. A possible third reason is that counselling alone is not enough to improve tolerance of adverse effects, and the mere occurrence of adverse effects is sufficient for women to decide to discontinue contraception, regardless of how adequate the information is about adverse effects (14).

This study is one of few to address discontinuation of hormonal contraception in the Gulf Region and is believed to be the first in Oman. It had a randomized design and adequate sample size. It provides some insights on factors that influence women's decision to discontinue contraception. Women in Oman share many religious and social values with women in other Arab states. So, it is likely that the results of this study can be generalized to other women in urban areas of other Gulf or Arab states.

The study had some limitations. This was a retrospective study with inherent disadvantages, including recall bias of participants and limited number of documented facts in the health records of the birth spacing clinic. Selection bias was also a limitation as $19.2 \%$ of the selected clients were excluded. The main reason was that the contact telephone numbers were those of husbands or a male family members who might not have been reachable. Also, most were mobile numbers that tend to be changed more often compared to landlines. The study sample was all from Muscat Region, which is considered an urban area, and this might limit the applicability of the findings to rural areas.

\section{Conclusion}

This study improves our knowledge of the rate of discontinuation of hormonal contraception and the causative factors in Oman, which can be used for population-specific counselling. It also provides reassurance regarding the frequency of some of the important adverse effects of these methods. Unlike in other populations, women in Oman are not reporting logistic difficulties in accessing or continuing their contraception. Breastfeeding women are the main users of hormonal contraception and POP is the main method. Therefore, it is important to look specifically into this group of women more closely in a prospective manner to assess further when and why they discontinue contraception and address their needs.

Funding: None.

Competing interests: None declared.

\section{Arrêt de la contraception hormonale à Oman : prévalence et raisons Résumé}

Contexte : Larrêt des contraceptifs hormonaux représente une part importante des besoins non satisfaits en matière de contraception.

Objectifs : Déterminer le taux d'arrêt et les raisons de l'arrêt de la contraception hormonale chez les femmes omanaises.

Méthodes : Il s'agissait d'une étude rétrospective de cohorte multicentrique, en deux étapes, menée en 2018 dans des centres de soins de santé primaires de la région de Mascate (Oman). Elle portait sur les utilisatrices de contraceptifs hormonaux récemment inscrites dans les cliniques de planification familiale de janvier à décembre 2016 et sur le déroulement des soins au cours des 12 mois suivants. Un entretien téléphonique a été mené pour compléter certaines données manquantes. Les méthodes contraceptives disponibles étaient les contraceptifs oraux combinés, les pilules à base de progestérone seule et l'acétate de médroxyprogestérone en injection retard.

Résultats : Nous avons inclus 404 femmes et $87,8 \%$ d'entre elles étaient allaitantes. À la fin de la première année, 268 femmes (66,3\%) avaient cessé d'utiliser leur méthode de contraception. Plus de la moitié (148/268; 55,2 \%) des arrêts de contraception ont été attribués à des effets indésirables, les plus fréquents étant les anomalies menstruelles (102/268 ; 38,1 \%). Seules 5,6\% des femmes (15/268) ont abandonné la contraception parce qu'elles désiraient une grossesse. Les partenaires et la logistique liée à la disponibilité des méthodes de contraception et leur accessibilité n'ont joué qu'un rôle minime dans l'arrêt de la contraception. L'âge des enfants et leur nombre n'ont pas influencé le taux d'arrêt.

Conclusion : La présente étude améliore nos connaissances sur le taux d'arrêt de la contraception hormonale et ses facteurs connexes à Oman, lesquelles peuvent être utilisées pour fournir des conseils spécifiques à la population. Les recherches futures devraient étudier les comportements en matière de contraception des femmes allaitantes afin de déterminer quand et pourquoi elles abandonnent leurs méthodes contraceptives. 


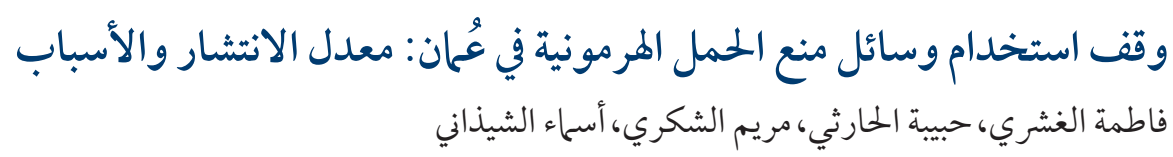

$$
\text { الأهداف: هلفية: يُعد وقف استخدام وسائل منع الحمل الهرمونية عاملًا مساهمًا مهاًّا في عدم تلبية الاحتياجات من وسائل منع الحمل. }
$$

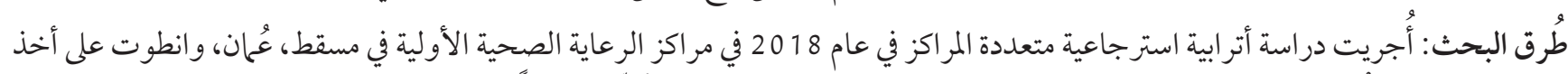

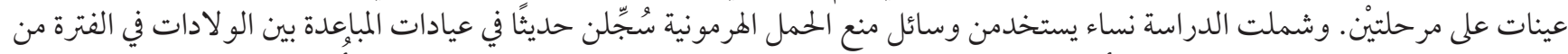

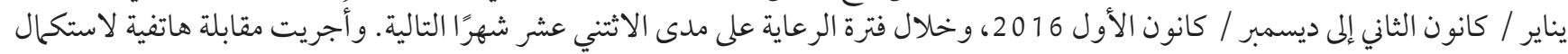

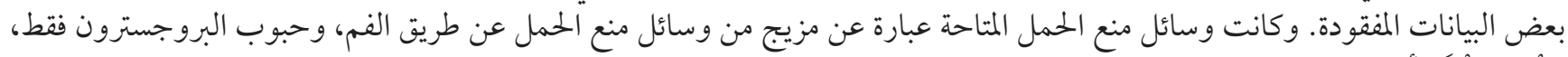

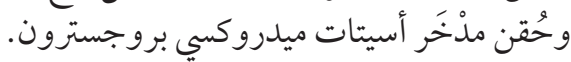

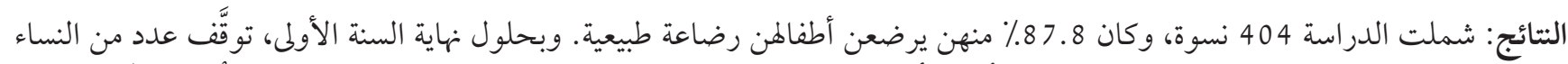

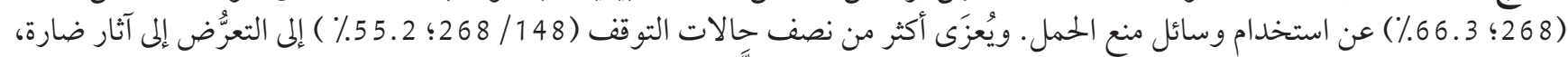

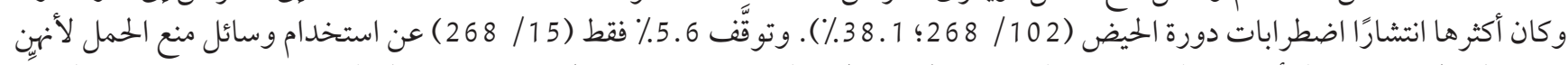

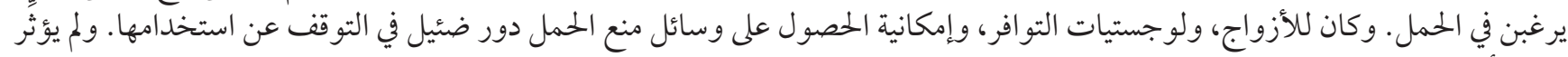

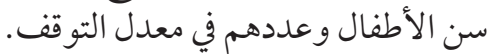

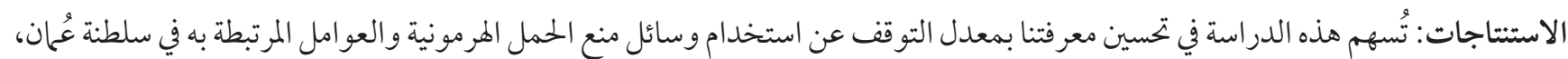

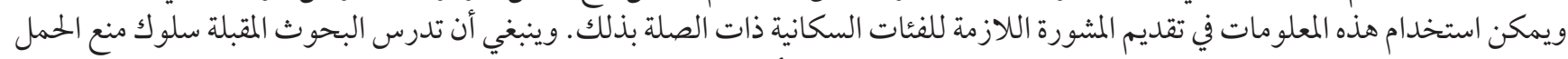

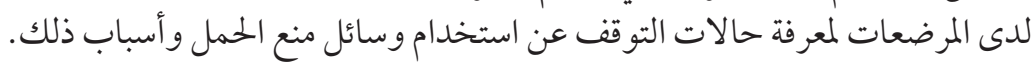

\section{References}

1. United Nations Department of Economic and Social Affairs Population Division. Contraceptive use by method 2019: data booklet. New York: United Nations; 2019 (https://www.un.org/en/development/desa/population/publications/pdf/family/ContraceptiveUseByMethodDataBooklet2019.pdf, accessed 24 May 2021).

2. Alkema L, Kantorova V, Menozzi C, Biddlecom A. National, regional, and global rates and trends in contraceptive prevalence and unmet need for family planning between 1990 and 2015: a systematic and comprehensive analysis. Lancet. 2013 May 11;381(9878):1642-52. https://doi.org/10.1016/So140-6736(12)62204-1 PMID:23489750

3. United Nations, Department of Economic and Social Affairs, Population Division. Estimates and projections of family planning indicators 2019. New York: Nunited Nations; 2019 (https://www.un.org/en/development/desa/population/publications/pdf/family/Figure_Model-based_estimates_Countries_2019.pdf, accessed 24 May 2021).

4. Alvergne A, Stevens R, Gurmu E. Side effects and the need for secrecy: characterising discontinuation of modern contraception and its causes in Ethiopia using mixed methods. Contracept Reprod Med. 2017 Oct 19;2:24. https://doi.org/10.1186/s40834-0170052-7 PMID:29201429

5. Hooper DJ. Attitudes, Awareness, Compliance and Preferences among Hormonal Contraception Users. Clin Drug Investig. 2010;30(11):749-63. https://doi.org/10.2165/11538900-000000000-00000 PMID:20818837

6. Millar SL, Cameron ST. Contraception in women with medical conditions. Obstet Gynaecol Reprod Med. 2019 Apr 1;29(4):111-7. https://doi.org/10.1016/j.ogrm.2019.01.011

7. Fruzzetti F, Perini D, Fornaciari L, Russo M, Bucci F, Gadducci A. Discontinuation of modern hormonal contraceptives: an Italian survey. Eur J Contracept Reprod Heal Care. 2016 Dec;21(6):449-54. https://doi.org/10.1080/13625187.2016.1234598 PMID:27715345

8. Littlejohn KE. Hormonal contraceptive use and discontinuation because of dissatisfaction: differences by race and education. Demography. 2012 Nov;49(4):1433-52. https://doi.org/10.1007/s13524-012-0127-7 PMID:22865164

9. Belete N, Zemene A, Hagos H, Yekoye A. Prevalence and factors associated with modern contraceptive discontinuation among reproductive age group women, a community based cross-sectional study in Humera town, northern Ethiopia. BMC Womens Health. 2018 Nov 22;18(1):190. https://doi.org/10.1186/s12905-018-0663-4 PMID:3046641

10. Murphy PA, Brixner D. Hormonal contraceptive discontinuation patterns according to formulation: investigation of associations in an administrative claims database. Contraception. 2008 Apr;77(4):257-63. https://doi.org/10.1016/j.contraception.2008.01.002 PMID:18342648

11. Barden-O'Fallon J, Speizer IS, Calhoun LM, Corroon M. Women's contraceptive discontinuation and switching behavior in urban Senegal, 2010-2015. BMC Womens Health. 2018;18:35. https://doi.org/10.1186/s12905-018-0529-9 PMID:29402320 
12 Bagnan Tonato JA, Lokossou MSHS, Sanni Imoru R, Aboubakar M, Obossou AAA, Tchegnonsi Tognon F, et al. Side effects of hormonal contraception of patients in the Family Planning of Centre University Hospital of Mother and Child Lagoon, Cotonou (Benin). Gynecol Obstet. 2017;7:48. https://doi.org/10.4172/2161-0932.1000452

13. Moreau C, Trussell J, Gilbert F, Bajos N, Bouyer J. Oral contraceptive tolerance: does the type of pill matter? Obstet Gynecol. 2007;109(6):1277-85. https://doi.org/10.1097/01.aog.0000260956.61835.6d PMID:17540798

14 Vitzthum VJ, Ringheim K. Hormonal contraception and physiology: a research-based theory of discontinuation due to side effects. Stud Fam Plann. 2005 Mar;36(1):13-32. https://doi.org/10.1111/j.1728-4465.2005.00038.x PMID:15828522

15 Directorate General of Primary Health Care - progress report. Muscat: Ministry of Health; 2015 (https://www.moh.gov.om/ documents/272928/o/Progress+Report+DGPHC/d3eea102-63d5-48fb-8404-2ff3514bodfo, accessed 24 May 2021).

16. Annual report 2017. New York: United Nations Childrens' Fund; 2017 (https://www.unicef.org/media/47861/file/UNICEF_Annual_Report_2017-ENG.pdf, accessed 24 May 2021).

17 Al-balushi MS, Ahmed MS, Islam MM, Khan HR. Contraceptive method choices among women in Oman : a multilevel analysis. J Data Sci. 2016;14(1):117-32. https://doi.org/10.6339/JDS.201601_14(1).0007

18. Birth spacing standard operating procedures, 3rd edition. Muscat: Department of Family \& Community Health, Directorate General of Health Affairs; 2012 (https://www.moh.gov.om/documents/272928/4017900/Birth+spacing+guidelines.pdf/74ce32cd-3b80-2a7a-8344-3a3f4dc2ab8d, accessed 24 May 2021).

19. National Centre for Statistics and Information data portal. Sultanate of Oman [website] (https://data.gov.om/OMHLTH2016/ health?tsId=1009710, accessed 24 May 2021).

20. Al Kindi RM, Al Sumri HH. Prevalence and sociodemographic determinants of contraceptive use among women in Oman. East Mediterr Health J. 2019 Oct 4;25(7):495-502. https://doi.org/10.26719/emhj.18.064 PMID:31612981

21. Thobani R, Jessani S, Azam I, Reza S, Sami N, Rozi S, et al. Factors associated with the discontinuation of modern methods of contraception in the low income areas of Sukh Initiative Karachi: a community-based case control study. PLoS One. 2019 Jul 3;14(7):1-13. https://doi.org/10.1371/journal.pone.0218952 PMID:31269086

22. Lopez LM, Grey TW, Stuebe AM, Chen M, Truitt ST, Gallo MF. Combined hormonal versus nonhormonal versus progestin-only contraception in lactation. Cochrane Database Syst Rev. 2105 Mar 20;(3):CD003988. https://doi.org/10.1002/14651858.cdoo3988. pub2 PMID:25793657

23. Kapp N, Curtis KM. Combined oral contraceptive use among breastfeeding women: a systematic review. Contraception. 2010 Jul;82(1):10-6. https://doi.org/10.1016/J.CONTRACEPTION.2010.02.001 PMID:20682139

24. Sabatini R, Cagiano R, Rabe T. Adverse effects of hormonal contraception. J Reprod Med Endocrinol. 2011;8(1):130-56. https:// www.kup.at/kup/pdf/10167.pdf

25. Diedrich JT, Zhao Q, Madden T, Secura GM, Peipert JF. Three-year continuation of reversible contraception. Am J Obstet Gynecol [Internet]. 2015 Nov;213(5):662.e1-662.e8. https://doi.org/10.1016/j.ajog.2015.08.001 PMID:26259905

26. Trussell J. Contraceptive failure in the United States. Contraception. 2011 May;83(5):397-404. https://doi.org/10.1016/j.contraception.2011.01.021 PMID:21477680

27. Edelman AB, Koontz SL, Nichols MD, Jensen JT. Continuous oral contraceptives: are bleeding patterns dependent on the hormones given? Obstet Gynecol. 2006 Mar;107(3):657-65. https://doi.org/10.1097/01.AOG.0000199950.64545.16 PMID:16507938

28. Sridhar A, Salcedo J. Optimizing maternal and neonatal outcomes with postpartum contraception: impact on breastfeeding and birth spacing. Matern Heal Neonatol Perinatol. 2017 Jan 13;3:1. https://doi.org/10.1186/s40748-016-0040-y PMID:28101373

29. Apgar BS, Greenberg GM. Using progestins in clinical practice. Am Fam Physician. 2000 Oct 15;62(8):1839-46. PMID:11057840

30. Al Riyami A, Afifi M, Mabry RM. Women's autonomy, education and employment in oman and their influence on contraceptive use. Reprod Health Matters. 2004 May;12(23):144-54. https://doi.org/10.1016/Sog68-8080(04)23113-5 PMID:15242223

31. Youssef RM. Contraception use and probability of continuation: community-based survey of women in southern Jordan. East Mediterr Health J. 2005;11(4):545-8. https://apps.who.int/iris/handle/10665/116978

32. Costa ARR, Palma F, Śa JL, Vicente L, Bombas T, Nogueira AM, et al. Impact of a women's counselling programme on combined hormonal contraception in Portugal - the IMAGINE Study. Eur J Contracept Reprod Heal Care. 2011 Dec;16(6):409-17. https://doi. org/10.3109/13625187.2011.608441 PMID:21942578

33. Mantha S, Karp R, Raghavan V, Terrin N, Bauer KA, Zwicker JI. Assessing the risk of venous thromboembolic events in women taking progestin-only contraception: a meta-analysis. BMJ. 2012;345:e4944. https://doi.org/10.1136/bmj.e4944

34. Barr NG. Managing adverse effects of hormonal contraceptives. Am Fam Physician. 2010 Dec 15;82(12):1499-506. https://www. aafp.org/afp/2010/1215/p1499.html

35. Allen R, Villavicencio J. Unscheduled bleeding and contraceptive choice: increasing satisfaction and continuation rates. Open Access J Contracept. 2016 Mar 31;7:43-52. https://doi.org/10.2147/oajc.s85565 PMID:29386936 